\title{
Reliability of routine double contrast examination of the large bowel: a prospective study of 2590 patients
}

\author{
F-TH FORK \\ From the Department of Diagnostic Radiology, University of Lund, Malmö General Hospital, Malmö \\ Sweden
}

SUMmARY A total of 2590 consecutive patients referred for double contrast examination (DCE) of the large bowel were followed up radiographically, clinically, endoscopically, and histopathologically during a four year period. The patients were put into two groups on the basis of the presence or absence of radiographic evidence of colonic disease at the first - that is, index examination. By comparing the findings obtained at the index double contrast examination with those obtained during follow up, the sensitivity, specificity, and accuracy of the index double contrast examination were all calculated at $0 \cdot 84$. The predictive value of a positive report was 0.93 and that of a negative report 0.70 . If, however, patients with normal double contrast examinations at the start of this series and not examined further during the follow up period were accepted as free from significant colonic disease, the predictive value of a negative report increased to 0.93 . Double contrast examination is thus a reliable method for showing the presence of colonic lesions and therefore considerably helps the management of a given case.

Cumulative clinical and experimental evidence suggest a strong connection between benign neoplastic polyps and carcinoma of the colon and rectum, indicating a tendency of the former to be the site of development of later gross malignant lesions. ${ }^{1-10}$ This fact provides cogent argument for the routine use of a radiographic procedure that is capable of detecting even minor polyps, especially as such lesions can now easily be removed through the colonoscope. ${ }^{81112}$ In an attempt to assess the accuracy of the double contrast examination of the large bowel - henceforth to be referred to as DCE and thereby to facilitate the clinical management of the patients in the light of the radiologist's report, a prospective study of patients, who were followed up for 40-80 months, was initiated.

\section{Methods}

\section{PATIENTS}

The clinical DCE material originally consisted of 2590 consecutive patients (1155 men and 1435 women) (Fig. 1) who underwent radiographic examination of the colon within a nine month period beginning in May 1976. These patients were

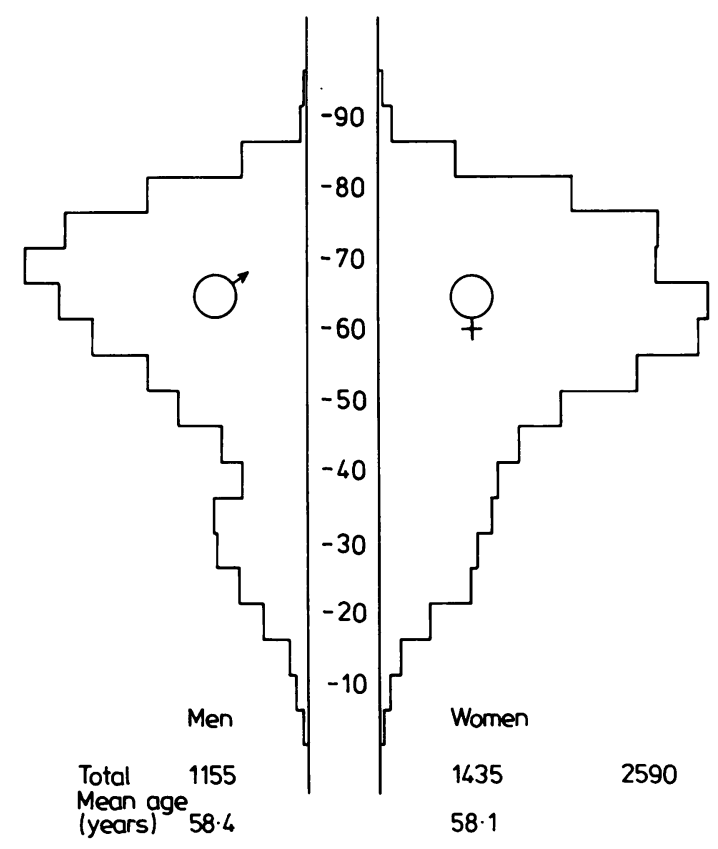

Fig. 1 Age and sex distribution of all 2590 patients. One patient was nine months old at referral for DCE. 
carefully followed up until June 1980 .

Fifty-five of these patients, however, were excluded because they had been examined with the single contrast method and 164 (mean age 60 years, range 4-95 years) because the bowel had not been properly prepared $(n=118)$ or because the patient could not cooperate $(n=46)$. This left 2371 patients for the present study who had been examined with DCE (index DCE). During the follow up period, 390 patients were re-examined once and 177 others twice or more with DC. The total number of DC examinations was 3405 .

Of the total number of patients included in this prospective study, 962 had had a DC examination previous to the initiation of this series.

The findings made at repeat DCE and colonoscopy, at operation, and at pathologic examinations were collected. In cases with rectal lesions according to the DCE or in the event of discord between the DCE and rectoscopy, the findings at rectoscopy (rigid instrument) were collected - that is, from 348 examinations in 296 patients. Colonoscopy was performed 170 times in 140 patients and surgery 155 times in 145; 137 patients were autopsied. A total of 793 tissue specimens from 650 patients were examined histologically and the findings were included in this series.

The patients' symptoms and the findings at earlier clinical examinations, as well as the indications for the first radiographic study, were noted, as were comments on previous DCE studies. In 2535 patients the index radiographic examinations were performed in accordance with the DCE method, described in detail by Fischer, Welin and others. ${ }^{13-21}$

Every DCE at Malmö General Hospital is routinely interpreted by two radiologists, one writing the report on the examination and the other showing it to the clinicians. During the present series the DCEs were also separately interpreted by two other independent, experienced radiologists who were unaware of previous clinical and radiographic reports. The interpretations were virtually always concordant and after three months, only one radiologist, the author, interpreted the remaining DCEs. If a positive result of a given examination did not accord with the previous, routinely written report, a new one was sent to the clinician. Thus, at least three independent radiologists had seen all the roentgenograms.

The patients were prepared for the examination in the way described previously. $22-24$ Ratings with regard to the radiographic technique were made, as was the assessment of the overall diagnostic quality of the study; score 1: adequate study; score 2: some reservation, not interfering with the dignostic interpretation; score 3: restricted quality; and score
4: not interpretable, corresponding to the 164 excluded patients.

Each DCE was categorised as normal, $N$, or abnormal, $a N$. In the latter case the lesions were defined as neoplastic, inflammatory, degenerative, or of other origin, and when possible, the lesions were grouped according to their position between the caecum and the rectum.

\section{Results}

The number of accepted index DCEs in this series was 2371. In 1101 patients the index DCE was within normal limits, but nevertheless 137 patients were re-examined once and 48 at least twice during the observation period (Tables 1 and $2 b$ ).

In 409 of the 1101 patients, DCEs had been performed previous to the index study.

The changes observed in the remaining 1270 patients (Table 2a, b) consisted merely of diverticulosis without signs of inflammation in 536 and various minimal findings - such as normal mucosa after major bowel surgery, spasm, or haemorrhoids alone - in 92 . This left 642 patients with significant changes.

Of these, 193 were re-examined once and 110 others at least twice. In 553 patients, DCEs had been made previous to the index study.

\section{VERIFICATION WITH DCE}

A. Index DCE normal (Table 2a, b; Fig. 2a, numerals within columns).

At the first follow up, the DCE still showed nothing abnormal in 108 patients, but displayed earlier undiagnosed colonic lesions in 29 (diverticula in five; polyps in 10; deformities due to extra colonic lesions in four patients; recurrent carcinoma in two; sequelae of irradiation in two; and mucosal inflammation in six). At the second follow up, polypoid lesions were confirmed in 11 patients, whereas in two others such polyps were excluded, thus confirming the index DCE. Further, in one patient a third examination revealed a previously undetected polyp.

Table 1 Number of patients with normal and abnormal index DCEs and one or more follow up DCEs.

\begin{tabular}{lrlrl}
\hline & \multicolumn{2}{l}{$D C E$ diagnoses } & \\
\cline { 2 - 4 } & \multicolumn{1}{l}{ Normal } & \multicolumn{2}{c}{ Abnormal } \\
\hline Index DCE & 1101 & $(409)$ & 1270 & $(553)$ \\
First follow up DCE & 185 & $(115)$ & 340 & $(157)$ \\
Subsequent DCEs & 48 & $(35)$ & 111 & $(48)$ \\
\hline
\end{tabular}

Numerals in parentheses denote patients with DCE studies before the index one. 
Table 2a Number of patients according to diagnoses

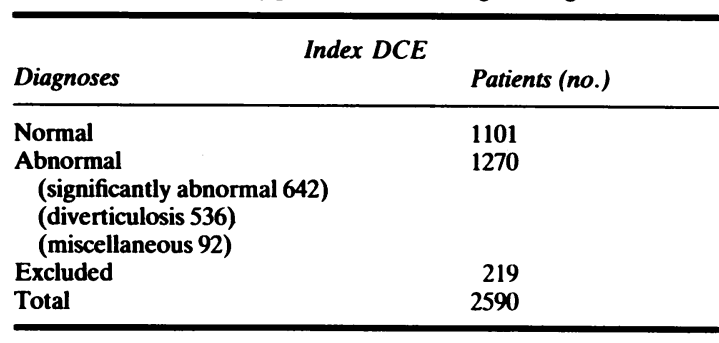

Table $2 \mathrm{~b}$ Number of patients examined once, twice, and three times with $D C E$, divided into those with normal, $N$, and abnormal $a N, D C E$ reports

\begin{tabular}{|c|c|c|c|c|c|}
\hline \multirow[b]{3}{*}{ Diagnoses at index $D C E$} & \multicolumn{5}{|c|}{ Patients } \\
\hline & \multirow{2}{*}{$\begin{array}{l}\text { One } \\
\text { DCE }\end{array}$} & \multicolumn{2}{|c|}{ Two DCES } & \multicolumn{2}{|c|}{ Three DCEs } \\
\hline & & $N$ & $a N$ & $N$ & $a N$ \\
\hline \multirow{3}{*}{$\begin{array}{l}\text { Normal } \\
\text { Diagnoses at } \\
\text { follow up DCEs }\end{array}$} & \multirow[t]{3}{*}{916} & \multicolumn{2}{|c|}{137} & \multicolumn{2}{|c|}{48} \\
\hline & & 108 & & 34 & 1 \\
\hline & & & 29 & 2 & 11 \\
\hline \multicolumn{6}{|l|}{ Significantly } \\
\hline abnormal & 339 & \multicolumn{2}{|c|}{193} & \multicolumn{2}{|c|}{110} \\
\hline Diagnoses at & & 35 & & 7 & 9 \\
\hline follow up DCEs & & & 158 & 12 & 82 \\
\hline
\end{tabular}
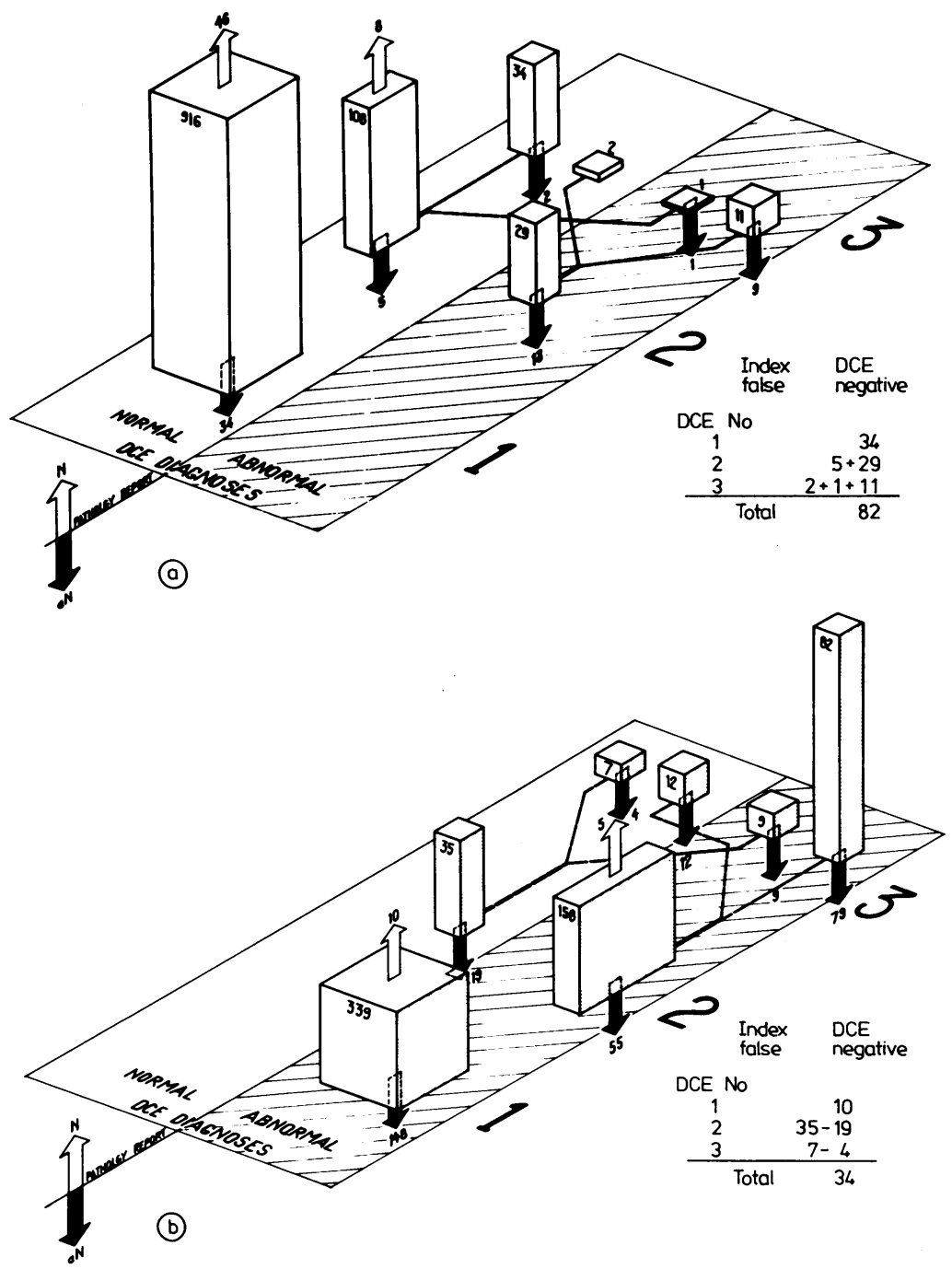

Fig. 2 Number of patients with normal, $A$, and abnormal, $B$, index $D C E s$, divided according to diagnoses at follow up studies. The columns denote numbers of patients categorised according to DCE diagnoses, and arrows the number of patients categorised according to histopathology.

( $\mathrm{N}=$ normal, $\mathrm{aN}=$ abnormal.) 
B. Index DCE abnormal (Table 2a, b; Fig. $2 b$, numerals within columns).

The first follow up of the 642 patients with significant colonic lesions at the index DCE still showed colonic changes in 158 , but no longer in 35 (inflammatory lesions were no longer demonstrable in 11 , although rectal biopsy in six revealed such lesions; the diagnosis of polyps at index DCE proved false positive in eight; polyps were removed after the index DCE in 13; and in three patients, deformities of the colon had disappeared).

The second follow up confirmed lesions in 91 patients. In 19 other patients, polypoid lesions had been removed after the index DCE in four and after the first follow up examination in 12 , whereas rectal changes seen in three patients at the index DCE were no longer demonstrable.

\section{VERIFICATION WITH OTHER METHODS}

$A$. Index DCE normal (Fig. 2a, numerals at arrows). Available tissue specimens from 80 patients without any demonstrable colonic abnormality at the index DCE showed missed polyps in 22 and mucosal inflammation in 12 , whereas in 46 (total colonoscopy in three and necropsy in 43) the specimens confirmed the normality of the large bowel. In another 26 patients, rectal biopsy showed nothing pathological. Of the 108 patients in whom neither the index DCE nor repeated roentgenography had disclosed anything abnormal, colonoscopy revealed polyps in five, whereas colonoscopy in one and autopsy of seven confirmed the normal appearance.

In 14 out of the 29 patients with radiographic changes at follow up, post mortem examinations were performed: in 13 the changes seen at DCE were proved and in one patient who had had a polyp removed endoscopically no additional pathological changes were found. Of the 34 patients in who a second DCE had shown no changes, specimens from two patients with macroscopically normal rectoscopies displayed mild, unspecific inflammatory changes.

Of 11 patients with demonstrable polypoid changes at the second follow up DCE, tissue specimens from nine were available and inflammation was seen in three specimens and polypoid tissue in six. In the single patient with normal follow up DCEs, biopsy specimens displayed polypoid tissue.

\section{B. Index DCE abnormal (Fig. 2b, numerals at arrows).}

In the 339 patients with radiographically significant colonic changes studied only once with DCE, the microscopic examination confirmed colonic lesions in 148 of these patients, but not in 10 (total colonoscopy in 12 confirmed mucosal changes in 10 , whereas biopsy specimens from two with quiescent ulcerative colitis and three with proctitis, at DCE and rectoscopy, were essentially normal; necropsy in 73 patients confirmed the lesions in all but five that is, no diverticular changes were seen; operation of 44 patients confirmed the radiographic changes in all; and rectoscopic biopsy specimens, in 26 others).

Of the remaining 303 patients - that is, those examined with one or two follow up DCEs (Table 2b; Fig. 2b), histological examination of available specimens from 188 confirmed the radiographic changes in 183 but not in five (subtle inflammatory disease shown at two DCEs in three patients, specimens of the rectum appeared essentially normal; a necropsy of two other patients failed to disclose any polyp in one and diverticular degeneration in another). Thus, at the index DCE there was an overdiagnosis in 34 patients but a correct diagnosis in 427 (Fig. 2b). Table 3 shows the number of over- and underdiagnoses. By placing the number of patients with verified normal and abnormal DCEs into a decision matrix, the sensitivity, specificity, and accuracy of a given DCE report was defined. ${ }^{25} 26$ Table 4 shows the results after the review of the follow up procedures. The sensitivity (defined as the quotient between the true positive studies and the number of diseased patients) and the specificity (the quotient of the true negative studies to the number of non-diseased patients) were respectively $\mathbf{0 . 8 4}$. The accuracy (defined as the quotient between the sum of the true positive plus negative patients and the whole groups) was also $0 \cdot 84$.

\section{Discussion}

As has been shown in earlier studies, ${ }^{5}$ Malmö is very suitable for epidemiological studies: one hospital for somatic diseases, serving a well defined population with a small annual percentage of people moving in and out, varying between $3.8 \%$ and $4.5 \%$ from 1958

Table 3 Number of patients with false index diagnosis proved by follow up studies

\begin{tabular}{|c|c|c|c|c|c|c|}
\hline & & Total & Polyps & Colitis & $\begin{array}{l}\text { Diverti- } \\
\text { cula }\end{array}$ & $\begin{array}{l}\text { Other } \\
\text { lesions }\end{array}$ \\
\hline A & $\begin{array}{l}\text { Number of false } \\
\text { negative index } \\
\text { diagnoses }\end{array}$ & 82 & 49 & 20 & 5 & 8 \\
\hline B & $\begin{array}{l}\text { Number of false } \\
\text { positive index } \\
\text { diagnoses }\end{array}$ & 34 & 9 & 13 & 6 & 6 \\
\hline
\end{tabular}

$\mathrm{A}=$ False negative diagnoses.

$\mathrm{B}=$ False positive diagnoses. 
Table 4 Number of patients with proved diagnosis of the index DCEs in a decision matrix

\begin{tabular}{llcl}
\hline & \multicolumn{2}{l}{ Result from follow up studies } \\
\cline { 2 - 3 } Index & $a N$ & $N$ & Total \\
\hline aN & 427 & 34 & 461 \\
N & 82 & 183 & 265 \\
Total & 509 & 217 & 726 \\
\hline
\end{tabular}

Sensitivity: $427 / 509=0 \cdot 84$; specificity: $183 / 217=0 \cdot 84$; accuracy: $(427+183) / 726=0 \cdot 84$; predictive value of a positive DCE: 427 । $461=0 \cdot 93$; predictive value of a negative DCE: $183 / 265=0 \cdot 70$. $\mathrm{N}=$ normal study; $\mathrm{aN}=$ abnormal study.

to 1980 . During this period the population increased from 221664 to 233000 (Statistical Department of the City of Malmö). Although the incidence of colorectal cancer is higher in southern Sweden than in the rest of the country, ${ }^{27}{ }^{28}$ the presented results of the roentgenography with the DCE method for colonic disease can probably be regarded as representative and valid for similar populations in Western industrialised countries.

The patients in our series were routinely referred for DCE - that is, without previous general screening for colonic diseases. The mean age of the patients was 60 years (range nine months-95 years), and the sex distribution was the same as in a series from our department in 1962. ${ }^{19}$

Since 1953, a radiographic examination of the colon has been routinely performed with the DCE method. Only crippled, elderly people with chronic disorders, or patients with acute colonic obstruction were examined with the single contrast procedure.

The initial aim of the study was to compare the diagnostic yield obtained at DCE with that obtained at single contrast radiography of the colon. This was, however, deemed unacceptable for ethical reasons, for the patient would have to be examined with both techniques on two separate occasions. Thus, to assess the diagnostic yield of the DCE procedure, the patients were followed up until July 1980 , it being assumed that any significant colonic or pericolonic disorder missed (carcinoma, inflammatory bowel disease, etc.) would be detected within this time. Most of the patients were not re-examined, a fact indicating absence of at least major colonic disorders.

The pathologist's report on biopsy and necropsy specimens was regarded as proof of the presence or absence of large bowel disease. The results of clinical, endoscopic, and repeat roentgenographic studies during the follow up period were thought to be the only way to come closer to the clinical truth and to avoid any bias in the evaluation of the figures when calculating the accuracy of the DCE method.
Uncomplicated diverticula of the colon are common in the elderly and middle aged population and are often asymptomatic. This group of patients was considered as not presenting significant disease or normal large bowels, and was consequently not included in the calculations of the above mentioned parameters.

The DCE studies before the index DCE were carried out several months to years before the beginning of our investigation (Table 1). A retrospective analysis of these studies was considered to lie beyond the scope of the present study. The number of such earlier examinations, however, was significantly larger in patients with an abnormal index DCE than in patients with a normal one $\left(\chi^{2}=10.39, p<0.001\right)$, indicating that abdominal symptoms in these patients were presumably referable to the large bowel.

The only way to offer the patient and his physician a test report of high accuracy is to comply with the prerequisites of the test itself. In this series, the test demands aimed at the patient were acceptably cleansed bowel and absence of moving artefacts. The percentage of patients who did not fulfil these criteria was $8.5 \%$ - namely, $118(4.6 \%)$ failed to comply with the instructions for bowel preparation; $55(2.1 \%)$ were in a poor general condition; and 46 $(1.8 \%)$ could not cooperate. Of these last 101 patients, $60 \%$ were 70 years of age of older.

Several reports on polyp detection and DCE indicate a high sensitivity of the method - that is, detection of a high percentage of known polyps. ${ }^{29-31}$ But hitherto no attention has been given to the specificity - namely, the number of normal DCEs versus the true number of non-diseased large bowels or to the overall accuracy of the DCE. Nor have patients been followed up for several years to disclose any colonic lesions primarily overlooked. Also, no efforts have been made to calculate the diagnostic capacity of DCE - that is, the predictive values of positive and negative DCE reports. Such figures are of great interest to physicians in their daily work ${ }^{26-32}$ for assessing the reliability of any laboratory examination. They are expressed as the quotient between the number of true positive roentgen examinations and the total number of positive DCEs and the true number of negative ones to the total number of negative DCE studies in our investigation, $427 / 461$ and $183 / 265$, respectively, yielding quotients of 0.93 and 0.70 . In other words, the risk of a false positive DCE in a given case was $7 \%$ and that of a false negative almost $30 \%$. The remaining 848 patients, however, with normal index DCEs and not examined further during the four year follow up were certainly free from significant colonic disease at the time of the index DCE, as 
these patients have not reappeared during this follow up period. Inclusion of these patients in the decision matrix raised the diagnostic specificity to $1031 / 1113$ - that is, 0.93 , which means that 93 out of 100 negative reports were correct. It should be kept in mind that these figures were obtained in clinically selected patients, which explains the high prevalence of colonic disease in this series $-70 \%$ (509 diseased patients of 726 patients followed up).

It is concluded, therefore, that routine roentgenography with adequate DCE is documented as being a reliable method for detecting or excluding patients with diseases of the colon. Assuming the absence of a colonic disorder in a patient with a normal index DCE and not further examined during at least three years to be correct, the DCE diagnosis was valid in 93 out of 100 instances.

This work was supported by the Swedish Medical Research Council, Project No B79-29X-4819-04.

\section{References}

1 Fitzgibbon G, Rankin FW. Polyps of the large intestine. Surg Gynecol Obstet 1931; 52: 1136-50.

2 Swinton NW, Warren S. Polyps of the colon and rectum and their relation to malignancy. JAMA 1939; 113: 1927-33.

3 Hultborn KA. The causal relationship between benign epithelial tumors and adenocarcinomas of the colon and rectum. Acta Radiol suppl 1954; 113: 1-71.

4 Gilbertsen VA. Proctosigmoidoscopy and polypectomy in reducing the incidence of rectal cancer. Cancer 1974; 34: 936-9.

5 Ekelund G. Colorectal polyps and carcinoma with special reference to their interrelationship. Lund: Thesis, 1974.

6 Ekeland GR, Lindström C. Histopathological analysis of benign polyps in patients with carcinoma of the colon and rectum. Gut 1974; 15: 654-63.

7 Enterline HT. Polyps and cancer of the large bowel. Pathology of the gastrointestinal tract. Curr Top Pathol 1976; 63: 95-141.

8 Gabrielsson N, Granqvist S, Ohlsén H, Sundelin P. Malignancy of colonic polyps. Diagnosis and management. Acta Radiol Diagnosis 1978; 19: 479-95.

9 Lane N, Fenoglio CM. The adenoma - carcinoma sequence in the stomach and colon. Gastrointest Radiol 1976; 1: 111-9.

10 Ekelund GR. Cancer risk with single and multiple adenomas: synchronous and metachronous tumors. In: Winawe S, Schottenfeld D, Sherlock R, eds. Colorectal cancer: prevention, epidemiology and screening. New York: Raven Press, 1980: 151-5.
11 Wolff WI, Shinya H. Colonfiberoscopy. JAMA 1971; 217: $1509-12$.

12 Wolff WI, Shinya H. Colonofiberoptic management of colonic polyps. Dis Colon Rectum 1973; 16: 87-93.

13 Fischer AW. Über eine neue röntgenologische Untersuchungsmethode des Dickdarms: Kombination von Kontrasteinlauf und Luftaufblähung. Klin Wochenschr 1923; 2: 1595-8.

14 Fischer $\mathrm{AW}$. Über die Röntgenuntersuchung des Dickdarms mit Hilfe einer Kombination von Lufteinblasung und Kontrasteinlauf. Langenbecks Arch Chir 1925; 134: 209-69.

15 Weber HM. The roentgenologic demonstration of polypoid lesions and polyposis of the large intestine. AJR 1931; 25: 577-89.

16 Weber HM. Carcinoma of the colon: its roentgenologic manifestations and differential diagnosis. Am J Cancer 1933; 17: 321-41.

17 Welin S. Modern trends in diagnostic roentgenology of the colon. Br J Radiol 1958; 31: 453-64.

18 Welin S. Über moderne röntgenologische Dickdarmdiagnostik unter besonderer Berücksichtingung der Doppelkontrastmethode. Münch Med Wochenschr 1958; 100: 1142-4.

19 Welin S. Über die rontgenologische Untersuchung des Dickdarmes mit der Doppelkontrastmethode. Radiologe 1962; 2: 87-100.

20 Hettler M. Zur Technik der Doppelkontrastdarstellung des Dickdarms. Radiologe 1962; 2: 115-24.

21 Miller RE, Brahme F. The clarity of good technic. Am J Dig Dis 1967; 12: 418-20.

22 Brown GR. A new approach to colon preparation for barium enema: preliminary report. Univ Mich Med Bull 1961; 27: 225.

23 Barnes MR. How to get a clean colon - with less efforts. Radiology 1968; 91: 948-9.

24 Rosengren JE, Åberg T. Cleansing of the colon without enemas. Radiologe 1975; 15: 421-6.

25 Lusted Lee B. Decision-making studies in patient management. $N$ Engl J Med 1971; 284: 416-24.

26 Galen RS, Gambino SR. Beyond normality: the predictive value and efficiency of medical diagnoses. New York: John Wiley, 1975.

27 The Swedish Cancer Registry. Cancer incidence in Sweden, 1977. Stockholm: The National Board of Health and Welfare, 1977.

28 National Bureau of Statistics. Causes of death 1976. Stockholm: National Bureau of Statistics, 1976.

29 Ott DJ, Gelfand DW, Wu WC, Kerr RM. Sensitivity of double-contrast barium enema: emphasis on polyp detection. AJR 1980; 135: 327-30.

30 Fork F-Th. Resultatvergleich zwischen der Doppelkontrastuntersuchung des Dickdarms und der Koloskopie mit Biopsie. In: Welin S, Welin G, eds. Die Doppelkontrastuntersuchung des Dickdarms, Erfahrungen mit der Welin-Modifikation. Stuttgart: Georg Thieme Verlag, 1980.

31 Fork F-Th. Double contrast enema and colonoscopy in polyp detection. Gut 1981; 22: 971-7.

32 Wulff HR. Rationel Klinik. (In Danish). Copenhagen: Scandinavian University Books Munksgaard, 1973. 